\title{
Pore size is a critical parameter for obtaining sustained protein release from electrochemically synthesized mesoporous silicon microparticles
}

Ester E. Pastor, Elaine Reguera-Nuñez, Eugenia Matveeva, Marcos Garcia-Fuentes

Mesoporous silicon has become a material of high interest for drug delivery due to its outstanding internal surface area and inherent biodegradability. We have previously reported the preparation of mesoporous silicon microparticles (MS-MPs) synthesized by an advantageous electrochemical method, and showed that due to their inner structure they can adsorb proteins in amounts exceeding the mass of the carrier itself. Protein release from these MS-MPs showed low burst effect and fast delivery kinetics with complete release in a few hours. In this work, we explored if tailoring the size of the inner pores of the particles would retard the protein release process. To address this hypothesis, three new MS-MPs prototypes were prepared by electrochemical synthesis, and the resulting carriers were characterized for morphology, particle size, and pore structure. All MS-MP prototypes had $90 \mu \mathrm{m}$ mean particle size, but depending on the current density applied for synthesis, pore size changed between 5 and $13 \mathrm{~nm}$. The model protein $\alpha$ chymotrypsinogen was loaded into MS-MPs by adsorption and solvent evaporation. In the subsequent release experiments, no burst release of the protein was detected for any prototype. However, prototypes with larger pores $(>10 \mathrm{~nm}$ ) reached $100 \%$ release in $24-$ $48 \mathrm{~h}$, whereas prototypes with small mesopores $(<6 \mathrm{~nm})$ still retained most of their cargo after $96 \mathrm{~h}$. MS-MPs with $\sim 6 \mathrm{~nm}$ pores were loaded with the osteogenic factor BMP7, and sustained release of this protein for up to two weeks was achieved. In conclusion, our results confirm that tailoring pore size can modify protein release from MS-MPs, and that prototypes with potential therapeutic utility for regional delivery of osteogenic factors can be prepared by convenient techniques. 


\section{Pore size is a critical parameter for obtaining sustained protein release}

2 from electrochemically synthesized mesoporous silicon microparticles

3

4 E. Pastor ${ }^{1}$, E. Reguera-Nuñez ${ }^{2}$, E. Matveeva ${ }^{1 *}$, M. Garcia-Fuentes ${ }^{2 *}$

$5 \quad{ }^{1}$ EM-Silicon Nanotechnologies S.L., Valencia, Spain

$6{ }^{2}$ Center for Research in Molecular Medicine and Chronic Diseases (CIMUS), Dep. Pharmacy

7 and Pharmaceutical Technology, and Health Research Institute (IDIS), Campus Vida,

8 Universidad de Santiago de Compostela, Spain

9

$10 *$ Corresponding authors:

11 Dr. Eugenia Matveeva: eumat@em-silicon.com

12 Prof. Marcos Garcia-Fuentes: marcos.garcia@usc.es

13

14 


\section{ABSTRACT}

17 Mesoporous silicon has become a material of high interest for drug delivery due to its

18 outstanding internal surface area and inherent biodegradability. We have previously reported the

19 preparation of mesoporous silicon microparticles (MS-MPs) synthesized by an advantageous

20 electrochemical method, and showed that due to their inner structure they can adsorb proteins in

21 amounts exceeding the mass of the carrier itself. Protein release from these MS-MPs showed low

22 burst effect and fast delivery kinetics with complete release in a few hours. In this work, we

23 explored if tailoring the size of the inner pores of the particles would retard the protein release

24 process. To address this hypothesis, three new MS-MPs prototypes were prepared by

25 electrochemical synthesis, and the resulting carriers were characterized for morphology, particle

26 size, and pore structure. All MS-MP prototypes had $90 \mu \mathrm{m}$ mean particle size, but depending on

27 the current density applied for synthesis, pore size changed between 5 and $13 \mathrm{~nm}$. The model

28 protein $\alpha$-chymotrypsinogen was loaded into MS-MPs by adsorption and solvent evaporation. In

29 the subsequent release experiments, no burst release of the protein was detected for any

30 prototype. However, prototypes with larger pores $(>10 \mathrm{~nm})$ reached $100 \%$ release in $24-48 \mathrm{~h}$,

31 whereas prototypes with small mesopores $(<6 \mathrm{~nm})$ still retained most of their cargo after $96 \mathrm{~h}$.

32 MS-MPs with $\sim 6 \mathrm{~nm}$ pores were loaded with the osteogenic factor BMP7, and sustained release

33 of this protein for up to two weeks was achieved. In conclusion, our results confirm that tailoring

34 pore size can modify protein release from MS-MPs, and that prototypes with potential

35 therapeutic utility for regional delivery of osteogenic factors can be prepared by convenient 36 techniques. 


\section{INTRODUCTION}

44 Mesoporous silicon (MS)-based materials are currently investigated in a variety of systems for drug delivery and tissue engineering applications (Anglin et al., 2008; Santos, 2014). Their main advantage lies on their outstanding surface area arising from the fine mesoporous structure that

47 allows remarkable drug loadings to be achieved just by plain adsorption (Prestidge et al., 2008).

48 MS is also biocompatible (Canham 1995; Godin et al., 2008; Salonen et al., 2008), and degrades

49 in the body to silicates $\left(\mathrm{SiO}_{2}\right)(\mathrm{Canham}$ 1995; Salonen et al., 2008; Pastor et al., 2009) that are

50 eliminated by renal excretion (Popplewell et al., 1998). Silicates have FDA GRAS status, and 51 even safety margins for silica nanoparticles administered intravenously start to be established

52 (Yu et al., 2013). Inspired by these properties, researchers have investigated silicon-based

53 carriers in a variety of formats (i.e. scaffolds, microparticles, nanoparticles, etc.) for delivering

54 hydrophobic and hydrophilic drugs (Anglin et al., 2008; Prestidge et al., 2008; Salonen et al., 55 2008). MS-based materials have also been proposed for delivering drug-loaded nanoparticles

56 within the concept of multistage delivery vehicles (Tasciotti et al., 2008).

57 Devices composed of a crystalline mesoporous silicon matrix are alternatives to silica

58 mesoporous structures (Kresge et al., 1992), but unlike those, they do not require a mesophase

59 template removal for their preparation. Mesoporous silicon can be prepared by stain-etching or

60 electrochemical anodizing of silicon. Both methods result in suitable mesoporous 
61 (nanostructured) materials, but the stain-etching method is less controlled with respect to pore

62 homogeneity, and often leaves an untreated crystalline silicon core inside the particles. Medical

63 materials prepared from stain-etched mesoporous silicon should be additionally checked for

64 complete removal of toxic nitric oxide residues. The electrochemical method for MS production

65 is therefore more medical-friendly, and recently its scalability has been considerably improved

66 (Makushok, Matveyeva \& Pastor, 2012).

67 The desired nanostructure of MS fabricated by electrochemical methods can be easily achieved

68 by a simple tuning of the preparation conditions, first of all, the applied current density. Even

69 though these inner nanostructure parameters (pore size, overall porosity, particle size, etc.) are

70 important for MS silicon drug carriers, they cannot assure by themselves optimal drug payloads.

71 The interaction between the drug and the carrier surface needs also to be engineered, and thus the

72 surface modification and functionalization of MS nanostructures has been extensively studied in

73 recent years (Jarvis, Barnes \& Prestidge, 2011; 2012; Barnes, Jarvis \& Prestidge, 2013). Among

74 different techniques, a simple oxidation is frequently performed that converts the outer surfaces

75 of crystalline mesoporous silicon to a mesoporous silica replica (Kresge et al., 1992).

76 In a previous publication from our group, MS microparticles (MS-MPs) with an average pore

77 size of $35 \mathrm{~nm}$ were prepared by an electrochemical method and stabilized by thermal oxidation.

78 These MS-MPs were successfully loaded by absorption equilibrium with two model proteins,

79 insulin and bovine serum albumin BSA (Pastor et al., 2011). Although these proteins were

80 released from a vehicle in a controlled manner, the process was fast $(\sim 80-100 \%$ release in less

81 than $2 \mathrm{~h}$ ), and consequently only suitable for some applications such as mucosal drug delivery.

82 Previous studies with hydrogels (Peppas et al., 2000), solid polymers (Sandor et al., 2001), and

83 other mesoporous materials (Santos, Radin \& Ducheyne, 1999) have shown that modulation of 
84 the inner nanostructure of the carrier can change the kinetics of drug release. We proposed that

85 similar principles should apply for controlling the release of proteins from electrochemically

86 synthesized MS-MPs. To address this hypothesis, we prepared MS-MPs with different pore sizes

87 and explored how changes in inner nanostructure can influence the release of loaded proteins.

88 This study was performed initially with the model protein $\alpha$-chymotrypsinogen $(\mathrm{aCT})$; then,

89 considering the bioactivity of MS materials for orthopedic regeneration (Canham, Reeves \&

90 Newey, 1999; Pastor et al., 2007; Sun et al., 2007), we loaded a protein of therapeutic interest for

91 this application, bone morphogenetic protein-7 (BMP7).

92

2. MATERIALS AND METHODS

\subsection{Materials}

Boron doped silicon with different resistivity, $0.01-0.02$ and 10-20 $\Omega \cdot \mathrm{cm}$, was purchased from $\mathrm{Si}$ Materials (Germany); wafer diameter was $100.0 \pm 0.5 \mathrm{~mm}$ and thickness of $525 \pm 25 \mu \mathrm{m}(\mathrm{pI}=2-$ 3.5). Fluoric acid (HF) (48 \%) was purchased from Riedel de Haën (Germany) and ethanol (96\%) from Panreac (Spain). Synthetic air $\left(\mathrm{N}_{2}\right.$ with $21 \%$ of $\left.\mathrm{O}_{2}\right)$ was provided from AbelloLinde S.A. (Spain). Avidin-peroxidase conjugate, $\alpha$-chymotrypsinogen A (aCT) from bovine pancreas $(\mathrm{pI}=9.5 ; \mathrm{Mw}=25.7 \mathrm{kDa})$, and 2,2'-azino-bis(3-ethylbenzthiazoline-6-sulfonic acid) were obtained from Sigma Aldrich (Spain). Recombinant human Bone Morphogenetic Protein-7 $(\mathrm{BMP} 7)(\mathrm{pI}=8.1 ; \mathrm{Mw}=28.8 \mathrm{kDa})$, polyclonal antibody rabbit anti-human BMP7, and biotinylated polyclonal antibody rabbit anti-human BMP7 were purchased from PeproTech (UK). All other solvents and chemicals used were high-grade purity. 


\subsection{Preparation of mesoporous silicon microparticles (MS-MPs)}

108 MS-MPs were obtained by an electrochemical method similar to that previously described by us

109 (Pastor et al., 2009). The main difference was the use of a 1:1 HF:Ethanol electrolyte, and special

110 cyclic regimes with etch-stops in order to improve the homogeneity of pore sizes distribution

111 along with the in-depth etching (Bychto et al., 2008). A constant current step (40 or $60 \mathrm{~mA} / \mathrm{cm}^{2}$

112 for 5-10 s) was followed by an etch-stop step (no current applied for 2-5 s) in cyclic periods.

113 After obtaining a MS layer of $\sim 150 \mu \mathrm{m}$ thickness, the electrochemical process was stopped, and

114 the Si wafer was washed thoroughly with distilled water, dried, and the porous material was

115 scratched from the remaining Si substrate. The obtained MS was subjected to a thermal oxidation

116 under a flow of synthetic air for 1 hour at 500 or $650{ }^{\circ} \mathrm{C}$ (Programat P200 equipped with a

117 vacuum pump VP3 and gas inlet, Ivoclar-Vivadent, Inc., US). To reduce the particle size to the

118 micrometer scale, the MS material was milled and sieved in cascade. The fraction between 75

119 and $100 \mu \mathrm{m}$ was selected for further studies. Henceforth, this fraction is referred to as MS-MPs.

120 The preparation conditions for the three different MS-MP prototypes studied in this work are

121 summarized in Table 1. For example, prototype B was prepared from Si wafer of 0.01-0.02

$122 \Omega \cdot \mathrm{cm}$ resistivity, under a current density of $40 \mathrm{~mA} / \mathrm{cm}^{2}$ applied for $10 \mathrm{~s}$, and then interrupted by

123 a $2 \mathrm{~s}$ interval of zero current (etch-stop). This regime was cyclically repeated for a few hours

124 until the $150 \mu \mathrm{m}$ porous layer was grown. After recollecting the porous material, the material 125 was thermally oxidized at 650 for one hour.

126

127 2.3. Characterization of MS-MPS

128 The porosity of the porous silicon materials was determined gravimetrically by comparing the

129 mass of the silicon wafer before and after anodizing as previously described (Pastor et al., 2011). 
130 Particle sizes were analyzed with a Mastersizer 2000 (Malvern Instruments, UK). MS-MPs

131 morphology was visualized by high resolution Scanning Electron Microscopy (SEM, Hitachi

132 S4500, Japan). Additionally, the Brunauer- Emmett-Teller (BET) surface area of the MS-MPs

133 was determined by $\mathrm{N}_{2}$ adsorption-desorption isotherms (Micrometrics ASAP 2020 V3.04H,

134 Micromeritics France S.A., France). Pore size was calculated from the same $\mathrm{N}_{2}$ adsorption data,

135 by the Barroett-Joyner-Halenda (BJH) method.

\section{2.4. Protein loading}

138 Protein loading was carried out by solvent evaporation (Prestidge et al., 2008). Briefly, $20 \mu \mathrm{L}$ of

139 the model protein aCT $(3 \mathrm{mg} / \mathrm{mL})$ or BMP7 $(5 \mu \mathrm{g} / \mathrm{mL})$ in aqueous solutions were added to a

140 fixed amount of MS-MPs (1 mg). The samples were gently vortexed for 10 seconds, and then

141 incubated under mild agitation at $37^{\circ} \mathrm{C}$ until total evaporation of solvent was reached and all

142 amounts of proteins incorporated into the MS-MPs (about 7 hours). The theoretical protein

143 loadings were: $60 \mu \mathrm{g} / \mathrm{mg}$ of MS-MPs for aCT, and $0.1 \mu \mathrm{g} / \mathrm{mg}$ of MS-MPs for BMP7. Loaded

144 MS-MPs were freeze-dried and stored at $-20^{\circ} \mathrm{C}$ until use.

146 2.5. In vitro release studies

147 Samples comprising $1 \mathrm{mg}$ of MS-MPs loaded with aCT or BMP7 were incubated with $500 \mu \mathrm{L}$ of

148 PBS (USP 38-NF 33, pH 7.4) under agitation (100 rpm, Heindolf, Titramax 1000, Germany) at

$14937^{\circ} \mathrm{C}$ (Heindolf, Inkubator 1000, Germany). At scheduled time points, release samples were

150 collected, and centrifuged at $7000 \mathrm{RCF}$ for $10 \mathrm{~min}$ at $4{ }^{\circ} \mathrm{C}$ (Beckman Coulter, Microfuge 22R).

151 The amounts of aCT in supernatants were determined by the bicinchoninic acid method (Micro

152 BCA protein Assay Kit, Pierce Biotechnology Inc., USA), and those of BMP7 by ELISA, as 
153 previously reported by us (Reguera-Nuñez et al., 2014). Amounts of released protein are

154 expressed as percentage of a total protein mass added at the loading stage since the whole mass

155 was considered as absorbed upon solvent evaporation.

3. RESULTS AND DISCUSSION

160

161

3.1 Characterization of different MS-MPs carriers

162

Mesoporous silicon microparticles (MS-MPs) were prepared by electrochemical etching,

163 thermal stabilization, and milling to reduce the particle sizes. The resulting powder was sorted

164 by sieving. The particles of the selected fraction (i.e. the MS-MPs) were irregular in shape, but

165 homogeneous in size (Fig. 1A). All the MS-MPs prototypes generated showed a normal

166 distribution of sizes with a mean value around $90 \mu \mathrm{m}$ (Figure 1B). This normal particle

167 distribution contrasted with our previous data where the particle distribution was log-normal

168 (Pastor et al., 2011); this might be related to the different particle fractions selected on each

169 work ( $90 \mu \mathrm{m}$ vs $33 \mu \mathrm{m}$ mean size, respectively). The mesoporous structure of MS-MPs

170 observed by high resolution SEM (Fig. 1C) revealed the regular and homogeneous pores

171 propagated along a single direction, as it is common for electrochemically prepared MS. The

172 SEM analysis, however, might not reveal the smallest pores of the materials due their well-

173 known resolution limits.

174 The inner structure for three different MS-MP prototypes (A-C) prepared under the conditions

175 summarized in Table 1 was characterized by $\mathrm{N}_{2}$ adsorption-desorption experiments (Fig. 1D). 
176 The data revealed very high specific surface areas for prototypes A and B ( $\left.>200 \mathrm{~m}^{2} / \mathrm{g}\right)$, but even

177 more for prototype $\mathrm{C}\left(350 \mathrm{~m}^{2} / \mathrm{g}\right)$ (Table 2$)$. The porosity of all samples was high ( $\left.>50 \%\right)$, and

178 the mean pore diameter was $\sim 12 \mathrm{~nm}$ for prototypes $\mathrm{A}$ and $\mathrm{B}$, and $\sim 6 \mathrm{~nm}$ for prototype $\mathrm{C}$. These

179 pore sizes were significantly smaller than MS-MPs prepared in our previous work (Pastor et al.,

180 2011), a result of the different preparation conditions. Due to their tighter internal structure, we

181 expected that the MS-MPs obtained in this work would be more suitable for the sustained

182 release of proteins.

183 Due to the limited number of prototypes studied and the important difference in parameters

184 observed, it is difficult to draw unequivocal conclusions on the relationships between the MS-

185 MPs preparation parameters (Table 1) and the resulting carrier properties (Table 2). Still, under

186 the tested preparation conditions, there is a positive correlation between the current density and

187 the specific surface area. Also, an inverse correlation between the applied current density and the

188 mean pore diameter can be noted, although the doping level of Si wafer might play a dominant

189 role in this correlation. Globally, the study confirms the possibility to prepare MS-MPs with

190 controllable mesoporous inner structures by the electrochemical method.

191

\section{3.2. Protein loading in MS-MPS}

193 After characterization of the different MS-MP prototypes, we characterized how these systems

194 are capable of loading and releasing two proteins, aCT and BMP7. The zymogen aCT was

195 selected as a model protein for screening studies since it has very similar physicochemical

196 properties ( $\mathrm{pI}$ and Mw) to BMP7 (see data on section 2.1), and we have previously observed

197 good correlation between encapsulation of both proteins (Reguera-Nuñez et al., 2014). ACT is a

198 zymogen physiologically activated by gut's endopeptidases, and does not activate under the 
199 conditions of the loading procedures and release tests applied in this work. For protein loading in

200 this work we decided to work under forcing conditions, and we evaporated a protein solution in

201 the presence of the MS-MPs at $37^{\circ} \mathrm{C}$. This method has the main advantage of forcing protein

202 encapsulation, which can be assumed to be close to $100 \%$. Because MS-MPs cannot be degraded

203 without harming the loaded protein, we were unable to quantify the loaded proteins. However,

204 from the final release point of our release studies (see 3.3 and 3.4), we can conclude that $>75 \%$

205 of aCT was loaded in all preparations, and $>60 \%$ of BMP7.

206 When using this loading method, the mechanisms that drive protein loading would be capillary

207 forces and adsorption from a continually concentrating solution (Karlsson et al., 2003). Other

208 possible mechanisms would be electrostatic interactions; after thermal oxidation the MS-MPs

209 surface bears a negative charge as the silicon oxides cover the entire porous network (Zangooie,

210 Bjorklund \& Arwin, 1998). This might affect the loading and release of cationic proteins such as

$211 \mathrm{aCT}$ and BMP7. Under the tested conditions, the final protein payloads per $\mathrm{mg}$ of the carrier

212 were $60 \mu \mathrm{g}$ for aCT and $0.1 \mu \mathrm{g}$ for BMP7.

213

2143.3 Pore size can control the release of a model protein (aCT) from MS-MPS

215 The release of loaded aCT from the three MS-MPs prototypes was analyzed in vitro (PBS,

$21637^{\circ} \mathrm{C}$ ). No burst release was observed for any of the tested prototypes, suggesting that most

217 protein is inside the pores and not adsorbed on the outer MS-MP surface (Fig. 2A). This

218 behavior is in agreement with our previous study on insulin and BSA, where despite of a faster

219 release $(<2 \mathrm{~h})$, only a moderate burst effect was observed $(\sim 30 \%)$ (Pastor et al., 2011). In the

220 present work, the burst effect was drastically reduced, presumably because of lower pore size of 
221 carriers, and because of the different procedures for protein loading (solvent evaporation vs.

222 adsorption equilibrium).

223 The MS-MPs investigated in this work were able to control protein release for longer periods of

224 time than the carriers previously reported by us (Pastor et al., 2011): for prototypes A and B a

$225 \sim 100 \%$ release was achieved in $30-40 \mathrm{~h}$ after incubation at $37^{\circ} \mathrm{C}$ in PBS. Prototype $\mathrm{C}$ showed

226 even more sustained kinetics with high retention of aCT still after $96 \mathrm{~h}$ (Fig. 2A). However,

227 after 2-weeks, sample $\mathrm{C}$ had released a $77.2 \% \pm 4.2(\mathrm{n}=3)$ of the loaded aCT. The slower

228 release should be associated with the nanostructure of the carriers, mainly to their pore size.

229 Mean pore size was $<15 \mathrm{~nm}$ for all prototypes studied here, and $33 \mathrm{~nm}$ in our previous work.

230 Prototype $\mathrm{C}$ possesses pores with a mean size of $\sim 6 \mathrm{~nm}$, half of those of prototypes $\mathrm{A}$ and $\mathrm{B}$,

231 and similar to the radius of gyration of aCT, $1.76 \mathrm{~nm}$ (Perkins et al., 1993). As observed in other

232 systems (Santos, Radin \& Ducheyne, 1999; Peppas et al., 2000; Sandor et al., 2001), when the

233 drug's radius of gyration is about the size of pores in the matrix, diffusion might be hindered,

234 and more sustained release kinetics achieved. When comparing the different prototypes studied

235 in this work, particle inner structure seems to be the critical factor modulating different release

236 kinetics.

237 When comparing the performance of the MS-MP prototypes from this work with those of our

238 previous work (Pastor et al., 2011), two additional factors need to be considered. First, the

239 effect of the chemical differences of the proteins tested. Insulin and BSA, used before, both bear

240 negative charges in PBS, and therefore, their attachment to MS-MPs surfaced by adsoption

241 shoud be driven mostly by hydrophobic interactions. On the other hand, aCT is positive in PBS,

242 and therefore, ionic interactions with the silicon oxide on the surface of MS-MPs can be

243 important to explain protein adsorption/desorption. Another parameter that could have some 
244 limited influence on protein release is the average particle dimensions, which was $33 \mu \mathrm{m}$ in our

245 previous work, and is $90 \mu \mathrm{m}$ here (Pastor et al., 2011). Particle dimension will influence the

246 diffusion length within the carrier for the protein. Recently, a new production method yielding

247 planar mesoporous silicon microparticles with a controlled thicknesses, porosity and pore sizes

248 has been reported (Makushok, Matveyeva \& Pastor, 2012). This new kind of materials might be

249 interesting for release mechanism studies since their lateral dimensions, perpendicular to the

250 pore axis, will play no important role in the release process.

2523.4 MS-MPs can achieve a 2-week sustained release of antigenically active BMP7

253 Based on promising data obtained with aCT protein, we tested MS-MP prototype $\mathrm{C}$ for the

254 controlled release of a therapeutic protein: BMP7. This protein is approved by FDA and other

255 regulatory agencies for orthopedic applications (OP-1 Putty and OP-1 Implant, Stryker, US),

256 and it is delivered through a collagen sponge with limited controlled release properties. This

257 limited controlled release has been linked to most of the treatment undesirable effects (Lane,

258 2001). MS-MPs were loaded with BMP7 as described in section 3.2, and the release kinetics of

259 the protein was analyzed. Consistently with the data obtained with aCT, a 2-week sustained

260 release was achieved (Fig. 2B). Once again, the release kinetics was characterized by low burst

$261(<10 \%)$, and by a sustained release profile for at least 14 days. Maximum release observed over

262 the experiment (28 days) was $\sim 70 \%$. Noteworthy, the quantification of BMP7 in the supernatant

263 was performed by ELISA, and thus, it guarantees the presence of the protein in its antigenically-

264 active form upon release. While antigenic activity is not a final proof of biological activity,

265 previous studies from our group using the same ELISA kit have found a relation between 
266 antigenic BMP7 and bioactive protein in a glioblastoma cancer stem cell model (Reguera-

267 Nuñez et al., 2014).

268 The release profile was fitted to zero-order, first-order, Higuchi and to the Kosmeyer-Peppas

269 models (Wizard - Statistics, Visualization, Data Analysis, Predictive Modeling, version 1.4,

270 Evan Miller ${ }^{\mathcal{O}}$, US). Fitting to the first-order and Higuchi models was adequate ( $<<0.008$ and

$271 \mathrm{p}<0.002$, respectively), but the best fit was achieved with the Kosmeyer-Peppas model (BMP

272 released $\left.\%=10.4 \cdot t(\text { days })^{0.64}, \mathrm{p}<0.001\right)$. The Kosmeyer-Peppas model is effective to describe

273 release systems where release kinetics might depend on several factors. The diffusional

274 exponent $(\mathrm{n}=0.64)$ indicates a process of anomalous diffusion (Korsmeyer et al., 1983; Peppas, 275 1985).

276 The similarities between aCT and BMP7 release kinetics reflect their similar physicochemical 277 properties. Indeed, BMP7 has a radius of gyration $\sim 3.5 \mathrm{~nm}$ (by analogy with other BMPs, 278 (Berry et al., 2006)) just slightly larger than aCT. It has also a basic isoelectric point (8.1) close 279 to that of aCT (9.5). These similarities result in consistent profiles for both proteins, and suggest 280 the robustness of the delivery technology.

281 In summary, we have achieved sustained release of BMP7 for at least two weeks by using 282 electrochemically synthesized MS-MPs. A preparation technology for the whole therapeutic 283 system is convenient, since both components, protein solution and pre-formed empty MS-MPs, 284 can be integrated together in an extemporaneous process. Due to the recently reported 285 osteointegration properties of the MS-MP carrier itself (Sun et al., 2007), one of the immediate 286 promising applications of this system would be in the bone regeneration area. 287 288 4. CONCLUSIONS 
290 Mesoporous silicon microparticles with controlled inner structure (pore size) can be prepared by

291 an electrochemical method, and loaded with proteins by simple adsorption and solvent

292 evaporation. Under optimized electrochemical conditions these microparticles present a

293 nanostructure with pore sizes below $10 \mathrm{~nm}$, and this small pore size is critical to provide

294 sustained release over several days for proteins. The medical potential of the electrochemically

295 synthesized mesoporous silicon microparticles is suggested by the two weeks sustained release

296 profile of the osteogenic factor BMP7.

297

298

\section{ACKNOWLEDGMENTS}

299 We thank Vika Makushok (EM Silicon Nanotechnology S.L.) for technical help on MS-MP

300 sample preparation and characterization, and Lidia Pereiro and Mariana Landin (University of

301 Santiago de Compostela) for technical help on $\mathrm{N}_{2}$ adsorption-desorption experiments.

302

303

\section{REFERENCES}

304

305

Anglin EJ, Cheng L, Freeman WR, Sailor MJ (2008). "Porous silicon in drug delivery devices 306 and materials." Advanced Drug Delivery Reviews 60: 1266-1277.

307 Barnes TJ, Jarvis KL, Prestidge CA (2013). "Recent advances in porous silicon technology for 308 drug delivery." Therapeutic Delivery 4(7): 811-823.

309 Berry R, Jowitt TA, Ferrand J, Roessle M, Grossmann JG, Canty-Laird EG, Kammerer

310 RA, Kadler KE, Baldock C (2006). "Role of dimerization and substrate exclusion in the 
311 regulation of bone morphogenetic protein-1 and mammalian tolloid." Proceedings of the

$312 \quad$ National Academy of Sciences 106: 8561-8566.

313 Bychto L, Makushok Y, Chirvony V, Matveeva E (2008). "Pulse electrochemical method for

314 porosification of silicon and preparation of porous Si dust with controllable particle size

315 distribution." Physica Status Solidi (c) 5(12): 3789-3793.

316 Canham LT (1995). "Bioactive silicon structure fabrication through nanoetching techniques."

$317 \quad$ Advanced Materials 7: 1033-1037.

318 Canham LT, Reeves CL, Newey JP (1999). "Derivatized mesoporous silicon with dramatically

319 improved stability in simulated human blood plasma." Advanced Materials 11: 1505-1507.

320 Godin B, Gu J, Serda RE, Ferrati S, Liu X, Chiappini C, Tanaka T, Decuzzi P, Ferrari M (2008).

321 "Multistage Mesoporous Silicon-based Nanocarriers: Biocompatibility with Immune Cells

322 and Controlled Degradation in Physiological Fluids." Controlled Release Newsletter 25: 9-11.

323 Jarvis KL, Barnes TJ, Prestidge CA (2011). "Surface chemical modification to control molecular

324 interactions with porous silicon." Journal of Colloid and Interface Science 363(1): 327-333.

325 Jarvis KL, Barnes TJ, Prestidge CA (2012). "Surface chemistry of porous silicon and implication

326 for drug encapsulation and delivery applications." Advances in Colloid and Interface Science

$327 \quad$ 175: $23-38$.

328 Karlsson LM, Tengvall PLundstrom I, Arwin H (2003). "Penetration and loading of human

329 serum albumin in porous silicon layers with different pore sizes and thicknesses." Journal of

$330 \quad$ Colloid and Interface Science 266: 40-47.

331 Korsmeyer RW, Gurny R, Doelker E, Buri P, Peppas NA (1983). "Mechanisms of solute release

332 from porous hydrophilic polymers." International Journal of Pharmaceutics 15(1): 25-35. 
333 Kresge CT, Leonowicz ME, Roth WJ, Vartuli JC, Beck JS (1992). "Ordered mesoporous

334 molecular sieves synthesized by a liquid-crystal template mechanism." Nature Materials 359 :

$335 \quad 710-712$.

336 Lane JM (2001). "BMPs: Why Are They Not in Everyday Use? ." The Journal of Bone \& Joint

337 Surgery 83(1): S161-162.

338 Makushok Y, Matveyeva Y, Pastor EL (2012). Nanostructured semiconductor materials, method

339 for the manufacture thereof and current pulse generator for carrying out said method

$340 \quad$ WO2012065825A3.

341 Pastor E, Matveeva E, Parkhutik V, Curiel-Esparza J, Millan MC (2007). "Influence of porous

342 silicon oxidation on its behaviour in simulated body fluid." Physica_Status Solidi (c) 4: 2136-

3432140.

344 Pastor E, Matveeva E, Valle-Gallego A, Goycooea FM, Garcia-Fuentes M (2011). "Protein

345 delivery based on uncoated and chitosan-coated mesoporous silicon microparticles." Colloids

346 and Surfaces B: Biointerfaces 88: 601- 609.

347 Pastor E, Salonen J, Vesa-Pekka LehtoV-P, Matveeva E (2009). "Electrochemically induced

348 bioactivity of porous silicon functionalized by acetylene." Physica Status Solidi (a) 206(6):

$349 \quad 1333-1338$.

350 Peppas NA (1985). "Analysis of Fickian and non-Fickian drug release from polymers."

$351 \quad$ Pharmaceutica Acta Helvetiae 60: 110-111.

352 Peppas NA, Bures P, Leobandung W, Ichikawa H (2000). "Hydrogels in pharmaceutical

353 formulations." European Journal of Pharmaceutics and Biopharmaceutics 50(1): 27-46. 
354 Perkins SJ, Smith KF, Kilpatrick JM, Volanakis JE, Sim RB (1993). "Modelling of the serine-

355 proteinase fold by X-ray and neutron scattering and sedimentation analyses: occurrence of the

356 fold in factor D of the complement system." Biochemical Journal 295: 87-99.

357 Popplewell J, King S, Day JP, Ackrill P, Fifield LK, Cresswell RG, di Tada ML, Liu K (1998).

358 "Kinetics of uptake and elimination of silicic acid by a human subject: a novel application of

359 32Si and accelerator mass spectrometry." Journal of Inorganic Biochemistry 69: 177-180.

360 Prestidge CA, Barnes TJ, Mierczynska-Vasilev A, Kempson I, Peddie F, Barnett C (2008).

361 "Peptide and protein loading into porous silicon wafers." Physica Status Solidi (a) 205: 311 -

362315.

363 Reguera-Nuñez E, C. Roca C, Hardy E, de la Fuente M, Csaba N, Garcia-Fuentes M (2014).

364 "Implantable controlled release devices for BMP-7 delivery and suppression of glioblastoma 365 initiating cells." Biomaterials 35(9): 2859-2867.

366 Salonen J, Kaukonen AM, Hirvonen J, Lehto V-P (2008). "Mesoporous Silicon in Drug

367 Delivery Applications." Journal of Pharmaceutical Sciences 97: 632-653.

368 Sandor M, Enscore D, Weston P, Mathiowitz E (2001). "Effect of protein molecular weight on

369 release from micron-sized PLGA microspheres." Journal of Controlled Release 76(3): 297-

370311.

371 Santos EM, Radin S, Ducheyne P (1999). "Sol-gel derived carrier for the controlled release of 372 proteins." Biomaterials 20(18): 1695-1700.

373 Santos HA (2014). Porous silicon for biomedical applications, Woodhead Publishing.

374 Sun W, Puzas JE, Sheu TJ, Liu X, Fauchet PM (2007). "Nano- to Microscale Porous Silicon as a 375 Cell Interface for Bone-Tissue Engineering." Advanced Materials 19: 921-924. 
376 Tasciotti E, Liu X, Bhavane R, Plant K, Leonard AD, Price BK, Cheng MM-C, Decuzzi P, Tour

377 JM, Robertson F, Ferrari M (2008). "Mesoporous silicon particles as a multistage delivery

378 system for imaging and therapeutic applications." Nature Biotechnology 3: 151-157.

379 Yu Y, Li Y, Wang W, Jin M, Du Z, Li Y, Duan J, Yu Y, Sun Z (2013). “Acute Toxicity of

380 Amorphous Silica Nanoparticles in Intravenously Exposed ICR Mice.” PLoS ONE 8(4):

381 e61346.

382 Zangooie S, Bjorklund R, Arwin H (1998). "Protein adsorption in thermally oxidized porous

383 silicon layers." Thin Solid Films 313-314: 825-830.

384 


\section{Table $\mathbf{1}_{\text {(on next page) }}$}

Table 1

Table 1 - Preparation conditions for different mesoporous silicon prototypes synthesized by the electrochemical method under special cyclic regimes with etch-stop (zero current) applied after each anodizing interval. Three different prototypes (A-C) were prepared and tested in this study, differing in silicon waver resistivity, current densities, etch-stop times, and thermal oxidation temperatures. 


\begin{tabular}{ccccc}
\hline & $\begin{array}{c}\text { Si wafer } \\
\text { Prosistivity } \\
(\Omega \mathrm{cm})\end{array}$ & $\begin{array}{c}\text { Current density } \\
\left(\mathrm{mA} / \mathrm{cm}^{2}\right) / \text { anodizing } \\
\text { time }(\mathrm{s})\end{array}$ & $\begin{array}{c}\text { Etch stop time } \\
(\mathrm{s})\end{array}$ & $\begin{array}{c}\text { Oxidation } \\
\text { temperature }\left({ }^{\circ} \mathrm{C}\right)\end{array}$ \\
\hline A & $0.01-0.02$ & $40 / 5$ & 5 & 500 \\
B & $0.01-0.02$ & $40 / 10$ & 2 & 650 \\
1 & $10-20$ & $60 / 5$ & 2 & 550 \\
\hline
\end{tabular}




\section{Table 2 (on next page)}

Table 2

Table 2 - Characteristics of the different mesoporous silicon microparticle prototypes. Data represent means \pm S.D., $n=3$. 
1 Prototype Specific surface $\left(\mathrm{m}^{2} / \mathrm{g}\right) \quad$ Porosity $(\%) \quad$ Pore diameter $(\mathrm{nm})$

\begin{tabular}{|c|c|c|c|}
\hline A & $210.2 \pm 13$ & $72 \pm 6$ & $11.4 \pm 0.7$ \\
\hline B & $224.9 \pm 16$ & $53 \pm 8$ & $12.4 \pm 3$ \\
\hline $\mathrm{C}$ & $350.8 \pm 21$ & $60 \pm 5$ & $5.8 \pm 0.4$ \\
\hline
\end{tabular}

2

3 
Figure 1 (on next page)

Figure 1

Fig 1 - Morphological and physicochemical properties of mesoporous silicon microparticles (MS-MPs): A) SEM image of MS-MPs (bar is $200 \mu \mathrm{m}$ ); B) Particle size distribution of the different MS-MP prototypes measured with a particle size analyzer; C) Example of a SEM image of the surface of MS-MPs (corresponding to prototype A, bar is $800 \mathrm{~nm}$ ); D) N2 adsorption isotherms, volume adsorbed vs. relative pressure (P/P0), for the different MS-MP prototypes. 


\section{Figure 2 (on next page)}

\section{Figure 2}

Fig 2 - In vitro release profile of (A) $\alpha$-chymotrypsinogen and (B) BMP-7 from MS-MPs prepared by the electrochemical method. Data represent means \pm S.D., $n=3$. 


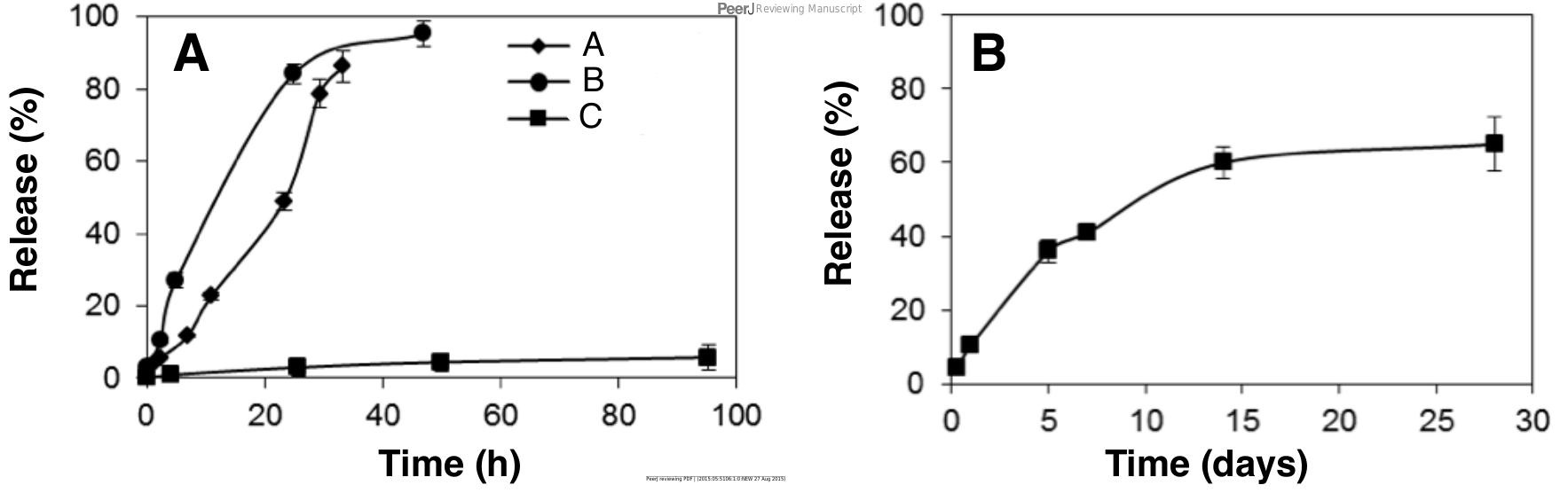

